\title{
Broadening the scope of epidemiology in conflict- affected settings: opportunities for mental health prevention and promotion
}

\author{
W. A. Tol ${ }^{1 *}$, S. J. Rees ${ }^{2}$ and D. M. Silove ${ }^{2}$ \\ ${ }^{1}$ Department of Mental Health, Johns Hopkins Bloomberg School of Public Health, Baltimore, MD, USA \\ ${ }^{2}$ Psychiatry Research and Teaching Unit, School of Psychiatry, University of New South Wales, Sydney, Australia
}

\begin{abstract}
This editorial proposes a shift in emphasis in the field of mental health epidemiology in conflict-affected settings. After a brief summary of the nature of contemporary armed conflicts, we consider the current and potential roles that epidemiology can play with regard to: (1) establishing the burden of mental disorders; (2) identifying risk and protective factors; and (3) intervention research. We advocate for improved methodological rigor; more attention to mixed methods approaches and multi-level longitudinal research; inclusion of the determinants of mental health beyond conflict-related violence; and consideration of a wider array of mental health outcomes. We particularly highlight the importance of expanding interest to epidemiological research that advances prevention and promotion interventions (e.g., in the early childhood period), in order to fill the gap between epidemiology and mental health practice in conflict-affected settings.
\end{abstract}

First published online 29 April 2013

Key words: epidemiology, low-income countries, mental health, PTSD.

In this editorial, we argue for a shift of attention in the field of mental health epidemiology in conflict-affected settings to include research that explicitly advances the development of mental health prevention and promotion interventions. We purposively use the term mental health epidemiology here as opposed to psychiatric epidemiology, to emphasize our focus on mental health as more than the absence of psychological symptoms - following the definition of health in the World Health Organization's constitution as 'a state of complete physical, mental and social well-being and not merely the absence of disease' (World Health Assembly, 2006).

Our focus here is on mental health epidemiology in settings of armed conflict. The Uppsala Conflict Data Program recorded 37 armed conflicts in 2011, defined as a minimum of 25-battle related deaths per year (Themner \& Wallensteen, 2012). In their classification, the armed conflict needs to include at least one government, but it is acknowledged that armed conflicts have become more fluid and fragmented, making them difficult to categorize (Machel, 2009). Current armed conflicts predominantly occur in low- and middle-income countries (LMIC), particularly countries in Africa

* Address for correspondence: Professor W. A. Tol, Department of Mental Health, Johns Hopkins Bloomberg School of Public Health, 624 N Broadway, Baltimore, MD, 21205-1996, USA.

(Email: wtol@jhsph.edu)
(41\%), Asia (35\%) and the Middle East (16\%). The majority of the armed conflicts recorded in 2011 were intra-state, that is, they took place between an internal opposition group and a government (Themner \& Wallensteen, 2012). Owing to their changing nature, contemporary armed conflicts disproportionately affect civilians: they are associated with structural human rights violations, including sexual violence, disappearances and torture; displacement; disruption of food supplies; systematic destruction of service and economic infrastructure; and disturbance of community support systems (Pedersen, 2002). Unfortunately, for many people in areas of armed conflict, conflict-related violence does not represent a sudden rupture in a life previously free of adversity. Rather, conflict-related violence often takes place against a pre-existing background of poverty and systematic marginalization. This creates the potential for vicious cycles in which armed conflicts exacerbate existing inequalities and vice versa (Tol et al., 2010a).

In settings of armed conflict, mental health epidemiology can have important functions for the promotion of mental health, and the prevention and treatment of mental disorders. We consider three key roles.

First, descriptive epidemiology may add value by detailing the prevalence rates of mental disorders. Such information may be useful for advocating for the necessity of a mental health response, defining priorities and decisions on allocation of resources. 
The usefulness of descriptive epidemiology with conflict-affected populations has, however, been seriously constrained by a number of factors, both substantive and methodological. An important methodological constraint has been the common use of symptom checklists that have not been validated for use in the population in which they are used (Kohrt et al., 2011). Using cut-off rates to establish rates of disorder, without knowledge on how this threshold compares with a gold standard (e.g., a psychiatric diagnostic interview), provides questionable prevalence rates. Without such validation, it is easy to mistake normal distress of populations in adverse situations with mental disorder (Rodin \& Van Ommeren, 2009). For example, the cut-off rates for the Hopkins Symptom Checklist and the Self Reporting Questionnaire had to be significantly adjusted for use in Afghanistan (Ventevogel et al., 2007).

Criterion validation is obviously a crucial task in ensuring useful descriptive epidemiology. However, criterion validation is enormously challenging in areas where the gold standard psychiatric diagnostic interview is not possible, e.g., because there are no trained psychiatrists or clinical psychologists available to conduct interviews. Criterion validation can also be challenged by the lack of a gold standard interview, e.g., in the case of intermittent explosive disorder (Silove et al., 2009; Al-Hamzawi et al., 2012) or when assessing prevalence of idioms of distress not described in international classification systems. Alternatives are to rely on paraprofessionals or consult with key informants about the absence or presence of disorder (Bolton, 2001; Kohrt et al., 2011), and to ensure that at least disability associated with symptoms is assessed. Even with these methods, distress and disorder will remain difficult to disentangle, and researchers should be mindful to avoid medicalizing normal distress arising from conditions of adversity.

A related issue has been the very large variance in prevalence rates found in epidemiological studies: 099\% for prevalence of post-traumatic stress disorder (PTSD) in 181 studies with conflict-affected populations (Steel et al., 2009). Much of the variance in these prevalence rates could be explained by methodological factors. For example, the unadjusted weighted prevalence rate for PTSD was $30.6 \%$. However, this rate was $15.7 \%$ in studies with sample sizes greater than $1000 ; 26.6 \%$ in studies with representative samples; and $24.6 \%$ in studies that used diagnostic interviews. Moreover, time since hostilities was a significant predictor of lower rates of PTSD, suggesting reduction in rates over time and the importance of longitudinal studies (Steel et al., 2009). Other methodological issues that may explain variance in prevalence rates concern the quality of translation of standardized instruments and the use of incorrect diagnostic criteria (Rodin \& Van Ommeren, 2009).

Given these methodological issues, we question the utility of a currently common approach to descriptive epidemiology in conflict-affected populations, i.e., the undertaking of small studies with non-validated symptom checklists for PTSD and depression in convenience samples. These studies may have an important role to play in advocating for mental health programmes. However, such advocacy could also be achieved through different means, including generalizing from the existing knowledge on prevalence rates of mental disorders as established by robust studies (Charlson et al., 2012); mixed methods participatory approaches that document perspectives on needs and resources as expressed by conflict-affected populations; and assessing the prevalence of individual symptoms without making claims regarding the prevalence of mental disorder (e.g., reporting that a certain percentage of people experienced extreme hopelessness, anxiety, or anger) - an approach taken by recent guidelines on assessment in humanitarian settings (WHO \& UNHCR, 2012).

Overall, an essential ethical principle should be to conduct research that minimizes the research burden in a population under distress while maximizing benefits in accruing vital knowledge that will guide priorities and approaches to intervention. A balance may be achieved by coordinating research with the existing health and community actors (to avoid duplicating efforts) and conducting thorough desk reviews to identify what is already known (for an example of such a review, see Kirmayer, 2010). From an ethical perspective, collecting new data in a separate study may represent an unreasonable burden if the same information is already available. Research burden can also be diminished by integrating questions on mental health in ongoing needs assessments by humanitarian actors. An additional ethical consideration concerns timeliness of information, as needs on the ground change quickly in acute conflict-affected settings. If descriptive epidemiology is to aid in the development of interventions, it is crucial that the results are provided in a time-frame that allows a response before needs have evolved (WHO \& UNHCR, 2012). Useful descriptive epidemiology requires continuous reflection on the balance between the excellence (e.g., the certainty that all aspects of the problem under study have been fully investigated) and relevance of research (e.g., the usefulness of findings to policy and practice) (Tol et al., 2012).

On a more conceptual level, a debate has focused on the application of psychiatric diagnostic categories from international classification systems in conflict-affected populations. Scholars have debated 
whether these psychiatric categories - originating in socio-cultural settings different from settings in which most armed conflicts occur - are relevant to these populations. Particularly the importance of PTSD for conflict-affected populations remains debated (Weiss et al., 2003). While the controversy regarding PTSD will not likely be resolved anytime soon, we would like to point to the importance of rapid ethnographic approaches in planning descriptive mental health epidemiology with conflict-affected populations (de Jong and van Ommeren, 2002; Bolton et al., 2009). Techniques such as free listing and pile sorting, semi-structured interviews with the affected population, key informant interviews, group interviews and participant observation can aid in the selection and development of instruments that measure mental health concepts with local relevance and validity (Miller et al., 2006; Tol et al., 2010b). Such techniques can also be employed in developing measures of functional impairment (Bolton \& Tang, 2002; Tol et al., 2011b), in order to establish which symptoms or symptom groups are most strongly associated with impairment in daily activities of conflict-affected populations (Tol et al., 2007; Silove et al., 2008). If these techniques are implemented in collaboration with national universities, relevant governmental agencies and non-governmental organizations, they may contribute to mental health research capacity building, and ultimately contribute to the development of a sustainable mental health infrastructure in conflict-affected LMIC (Silove et al., 2011). An important challenge here lies in how to connect knowledge of local experience of mental health on the one hand with the need for international comparison and exchange of knowledge on the other hand. One way of addressing this problem may consist of local adaptation of standardized measures using the same mixed methods procedures across socio-cultural settings: content of the measures may then vary, but overall comparison remains possible.

In addition, we would like to stress the importance of attention to mental health beyond PTSD, including neuropsychiatric disorders such as psychosis, substance use disorders and dissociative disorders. For example, an epidemiological study in conflict-affected Timor-Leste found high rates of psychotic-like symptoms (predicted by traumatic events) which were strongly associated with disability (Silove et al., 2008; Soosay et al., 2012). Similarly, rapid assessments in a variety of refugee populations have identified alcohol and substance use disorders as an important mental health problems (Ezard et al., 2011). Very little research has focused on dissociative disorders in conflict-affected settings, even though they have been shown to be associated with exposure to traumatic events and may be a common idiom of distress in conflict-affected populations (van Duijl et al., 2010).

Second, analytic epidemiology may contribute through the identification of risk and protective factors for mental health outcomes. A recent study aimed at identifying research priorities in humanitarian settings for the next decade placed this area of epidemiology at the top of the priority list. Overall, strong consensus was found in this study for a research agenda that generates practical knowledge that could be translated to immediate tangible benefits for programming in humanitarian settings, rather than addressing the key debates that have dominated the academic literature so far. The top 10 of most highly prioritized research questions focused on problem analysis: 'What are the stressors faced by populations in humanitarian settings?' (\#1); 'How do affected populations themselves describe and perceive mental health and psychosocial problems in humanitarian settings?' (\#3); 'What are the major protective factors (including individual [e.g., coping, hope] and contextual [e.g., justice mechanisms, religious practices]) for mental health and psychosocial problems in humanitarian settings?' (\#7) and 'To what extent do current mental health and psychosocial supports address locally perceived needs?' (\#9) (Tol et al., 2011c, 2012).

With regard to risk factors, the existing research has confirmed that past exposure to conflict-related events (particularly torture) is an important predictor of worse mental health outcomes (Steel et al., 2009). In addition to exposure to traumatic events, new research is confirming that exposure to current adversity (e.g., poverty, lack of access to basic services) is highly relevant to mental health in conflict-affected populations (Brooks et al., 2011). For example, a recent study found that current perceived needs mediated the relation between traumatic events and psychological distress in both Iraqi and Bhutanese refugees (Jordans et al., 2012). Similar findings have been reported with refugees in Darfur (Rasmussen et al., 2010) and Sri Lankan youth (Miller et al., 2009). In children and adolescents affected by armed conflict, longitudinal research has shown the importance of post-conflict social and economic hardship (Betancourt et al., 2010), as well as family violence (Panter-Brick et al., 2011) as risk factors for psychological symptoms over time. Taken together, these research findings suggest that epidemiology in conflict-affected settings should be inclusive of the determinants of mental health that have been identified in LMIC more generally, i.e., poverty, marginalization and diverse forms of violence (Patel et al., 1999; Rees et al., 2011).

The study of protective factors has been a growing area of interest, particularly in the area of resilience, that is, good mental health outcomes despite exposure 
to adversity. A recent systematic review of studies in LMIC on promotive and protective factors in children affected by armed conflict identified 53 studies, 38 of which were quantitative and 15 of which applied qualitative or mixed methods. This review found important methodological shortcomings in this area of research: most studies were cross-sectional in nature; few studies measured positive outcomes in addition to psychological symptoms; and more consistent effort to measure predictors and outcomes in culturally sensitive ways is necessary (Tol et al., 2013). The review also identified only two studies focused on the early childhood period, even though this area understandably is regarded as the most costeffective period for preventive efforts (Heckman, 2006; Shonkoff \& Garner, 2012). Authors of similar reviews have all emphasized that an important future research direction among conflict-affected children and adolescents concerns contextually sensitive longitudinal epidemiological research focused on identifying modifiable risk and protective factors at multiple levels of the social ecology (e.g., individual-, family-, school-, community-levels) (Reed et al., 2012; Betancourt et al., 2013). Such a multi-level model research could, for instance, focus on family-level variables by sampling family units rather than individuals within households (Farhood et al., 1993), which is the current norm.

The importance of heeding socio-cultural context is reinforced by findings on the complexity of resilience. Determinants of mental health have been shown to have different impacts depending on the phase of conflict, gender and developmental stage. Protective factors in one setting may be risk factors in other settings. For example, political affiliation appeared protective among Nepali former child soldiers (Kohrt et al., 2010), but the reverse was observed in Bosnian adolescents (Jones, 2002). Such complexity warns against pre-packaged resilience promotion approaches in conflict-affected populations, but rather suggests the need for careful assessment of risk - and protective factors in new settings to inform development of mental health prevention and promotion interventions that are tailored to context (Tol et al., 2013).

This links to the third area where epidemiology may contribute to mental health of conflict-affected populations; that is intervention research. The current emphasis in global mental health research in general is on the scaling up of evidence-based treatments for mental disorders, by making them available in primary care settings (World Health Organization, 2010; Patel, 2011). Although crucial, there is also consensus that a key 'grand challenge' rests in advancing prevention and implementation of early interventions for mental disorders (Collins et al., 2011). A systematic review of rigorous evaluations of mental health and psychosocial support interventions in humanitarian settings found a large gap between research and practice in this regard. Whereas a survey of practice showed the popularity of preventive approaches (e.g., community-based social supports, structured social activities including child-friendly spaces, raising awareness and psycho-education), the most rigorous evaluations had focused on specialized interventions, such as psychological therapies for PTSD (Tol et al., 2011a).

We realize that pursuing a prevention agenda is easier said than done. A key challenge in pursuing such an agenda is that many of the systemic determinants of mental health are highly entrenched (e.g., systematic marginalization of ethnic or religious groups, violence against women) and outside the influence of mental health practitioners. Nevertheless, it does not seem sensible to treat the mental health consequences of living in areas of armed conflict, without attention to what causes mental health concerns - and this is where epidemiology has an essential role to play. Pursuing preventive efforts will require mental health professionals and researchers to step outside the confines of clinics and disciplinary confines and engage with advocacy groups, community leaders, policy makers and other key stakeholders that affect social change. It will also require the development of an additional skill-set among mental health professionals in integrating their concerns in for example human rights protection efforts, social welfare and the education system. And it demands from mental health researchers that they collaborate with a wide variety of specialists, e.g., in the fields of agriculture, nutrition, poverty alleviation, political science and human rights, to have their research concerns addressed in multidisciplinary efforts. Throughout this process, it is crucial that mental health practitioners and researchers first listen to the needs and possibilities for social action as expressed by these stakeholders, in order to avoid the uni-directional imposition of cultural values from the outside.

A particularly attractive research strategy concerns preventive interventions in early childhood, given evidence that stress during that developmental period has adverse consequences across the life course. As brain development proceeds sequentially, with later development building on earlier achievements, prevention efforts in this period can have multiplicative impacts across the life span (Shonkoff \& Garner, 2012). This could be achieved through, for example, treatment of maternal mental disorders, developing parenting skills and enhancing the quality of the home environment, including the prevention of domestic violence. Although evidence-based strategies exist to improve early childhood outcomes in LMICs (e.g., breastfeeding, parenting and pre-school programmes), 
there is a need for the development of integrated interventions that can address the multiple stressors that children are commonly exposed to (Engle et al., 2011). More evidence is required to determine whether the treatment of maternal mental disorders will improve developmental outcomes, or how integrated nutrition and early stimulation can best be applied in conflict-affected settings (Morris et al., 2012).

\section{Conclusions}

This editorial provides a number of recommendations for expanding the role of epidemiologists in conflict-affected settings. With regard to descriptive epidemiology, we advocate for epidemiologists to improve methodological rigor; to consider additional (mixed methods) approaches; and to focus on mental health concerns beyond PTSD and depression. We also argue for more attention to analytic epidemiology. Within analytic epidemiology, we propose studying the determinants of mental health identified in LMIC, in general, including diverse forms of violence, marginalization and poverty; to conduct longitudinal multi-level research; and the systematic inclusion of protective factors and positive aspects of wellbeing. Finally, with regard to intervention research, we highlight the importance of epidemiological research that informs the development and evaluation of mental health prevention interventions, and believe the early childhood period would be a particularly promising period to focus efforts on. In our opinion, implementation of these recommendations would contribute to narrowing the gap between epidemiological research and practice in conflict-affected settings.

\section{Financial Support}

This research received no specific grant from any funding agency, commercial or not-for-profit sectors.

\section{Conflict of Interest}

None.

\section{References}

Al-Hamzawi A, Al-Diwan JK, Al-Hasnawi SM, Taib NI, Chatterji S, Hwang I, Kessler RC, Mclaughlin KA (2012). The prevalence and correlates of intermittent explosive disorder in Iraq. Acta Psychiatrica Scandinavica 126, 219-228.

Betancourt TS, Brennan RT, Rubin-Smith J, Fitzmaurice GM, Gilman SE (2010). Sierra Leone's former child soldiers: a longitudinal study of risk, protective factors, and mental health. Journal of the American Academy of Child and Adolescent Psychiatry 49, 606-615.

Betancourt TS, Borisova I, Williams TP, Meyers-Ohki SE, Rubin-Smith JE, Annan J, Kohrt BA (2013). Research review: psychosocial adjustment and mental health in former child soldiers - a systematic review of the literature and recommendations for future research. Journal of Child Psychology and Psychiatry 54, 17-36.

Bolton P (2001). Cross-cultural validity and reliability testing of a standard psychiatric assessment instrument without a gold standard. Journal of Nervous and Mental Disease 189, 238-242.

Bolton P, Tang AM (2002). An alternative approach to cross-cultural function assessment. Social Psychiatry and Psychiatric Epidemiology 37, 537-543.

Bolton P, Tol WA, Bass JK (2009). Combining qualitative and quantitative research methods to support psychosocial and mental health programmes in complex emergencies. Intervention: International Journal of Mental Health, Psychosocial Work and Counselling in Areas of Armed Conflict 7, 181-186.

Brooks R, Silove D, Steel Z, Steel CB, Rees S (2011). Explosive anger in postconflict Timor Leste: interaction of socio-economic disadvantage and past human rights-related trauma. Journal of Affective Disorders 131, 268-276.

Charlson FJ, Steel Z, Degenhardt L, Chey T, Silove D, Marnane C, Whiteford HA (2012). Predicting the impact of the 2011 conflict in Libya on population mental health: PTSD and depression prevalence and mental health service requirements. PLoS ONE 7, e40593.

Collins PY, Patel V, Joestl SS, March D, Insel TR, Daar AS, Anderson W, Dhansay MA, Phillips A, Shurin S, Walport M, Ewart W, Savill SJ, Bordin IA, Costello EJ, Durkin M, Fairburn C, Glass RI, Hall W, Huang Y, Hyman SE, Jamison K, Kaaya S, Kapur S, Kleinman A, Ogunniyi A, Otero-Ojeda A, Poo MM, Ravindranath V, Sahakian BJ, Saxena S, Singer PA, Stein DJ (2011). Grand challenges in global mental health. Nature 475, 27-30.

De Jong JTVM, van Ommeren M (2002). Toward a culture-informed epidemiology: combining qualitative and quantitative research in transcultural contexts. Transcultural Psychiatry 39, 422-433.

Engle PL, Fernald LC, Alderman H, Behrman J, O'gara C, Yousafzai A, De Mello MC, Hidrobo M, Ulkuer N, Ertem I, Iltus S (2011). Strategies for reducing inequalities and improving developmental outcomes for young children in low-income and middle-income countries. Lancet 378, 1339-1353.

Ezard N, Oppenheimer E, Burton A, Schilperoord M, Macdonald D, Adelekan M, Sakarati A, van Ommeren M (2011). Six rapid assessments of alcohol and other substance use in populations displaced by conflict. Conflict and Health 5, 1 .

Farhood L, Zurayk H, Chaya M, Saadeh F, Meshefedjian G, Sidani T (1993). The impact of war on the physical and mental health of the family: the Lebanese experience. Social Science and Medicine 36, 1555-1567.

Heckman JJ (2006). Skill formation and the economics of investing in disadvantaged children. Science 312, 19001902. 
Jones L (2002). Adolescent understandings of political violence and psychological well-being: a qualitative study from Bosnia Herzegovina. Social Science and Medicine 55, 1351-1371.

Jordans MJ, Semrau M, Thornicroft G, van Ommeren M (2012). Role of current perceived needs in explaining the association between past trauma exposure and distress in humanitarian settings in Jordan and Nepal. British Journal of Psychiatry 201, 276-281.

Kirmayer LJ (2010). Culture and Mental Health in Haiti: A Literature Review. World Health Organization \& Pan American Health Organization: Geneva.

Kohrt BA, Jordans MJ, Tol WA, Perera E, Karki R, Koirala S, Upadhaya N (2010). Social ecology of child soldiers: child, family, and community determinants of mental health, psychosocial well-being, and reintegration in Nepal. Transcultural Psychiatry 47, 727-753.

Kohrt BA, Jordans MJ, Tol WA, Luitel NP, Maharjan SM, Upadhaya N (2011). Validation of cross-cultural child mental health and psychosocial research instruments: adapting the depression self-rating scale and child PTSD symptom scale in Nepal. BMC Psychiatry 11, 127.

Machel G (2009). Children and Conflict in a Changing World: Machel Study 10-Year Review. UNICEF: New York.

Miller KE, Kulkarni M, Kushner H (2006). Beyond trauma-focused psychiatric epidemiology: bridging research and practice with war-affected populations. American Journal of Orthopsychiatry 76, 409-422.

Miller KE, Fernando G, Berger DE (2009). Daily stressors in the lives of Sri Lankan youth: a mixed methods approach to assessment in a context of war and natural disaster. Intervention: International Journal of Mental Health, Psychosocial Work and Counselling in Areas of Armed Conflict 7, 187-203.

Morris J, Jones L, Berrino A, Jordans MJ, Okema L, Crow C (2012). Does combining infant stimulation with emergency feeding improve psychosocial outcomes for displaced mothers and babies? A controlled evaluation from northern Uganda. American Journal of Orthopsychiatry 82, 349-357.

Panter-Brick C, Goodman A, Tol WA, Eggerman M (2011). Mental health and childhood adversities: a longitudinal study in Kabul, Afghanistan. Journal of the American Academy of Child and Adolescent Psychiatry 50, 349-363.

Patel V (2011). A renewed agenda for global mental health. Lancet 378, 1441-1442.

Patel V, Araya R, De Lima M, Ludermir A, Todd C (1999). Women, poverty and common mental disorders in four restructuring societies. Social Science and Medicine 49, 1461-1471.

Pedersen D (2002). Political violence, ethnic conflict, and contemporary wars: broad implications for health and social well-being. Social Science and Medicine 55, 175-190.

Rasmussen A, Nguyen L, Wilkinson J, Vundla S, Raghavan S, Miller KE, Keller AS (2010). Rates and impact of trauma and current stressors among Darfuri refugees in Eastern Chad. American Journal of Orthopsychiatry 80, 227-236.

Reed RV, Fazel M, Jones L, Panter-Brick C, Stein A (2012). Mental health of displaced and refugee children resettled in low-income and middle-income countries: risk and protective factors. Lancet 379, 250-265.
Rees S, Silove D, Chey T, Ivancic L, Steel Z, Creamer M, Teesson M, Bryant R, Mcfarlane AC, Mills KL, Slade T, Carragher N, O'Donnell M, Forbes D (2011). Lifetime prevalence of gender-based violence in women and the relationship with mental disorders and psychosocial function. Journal of the American Medical Association 306, 513-521.

Rodin D, van Ommeren M (2009). Commentary: explaining enormous variations in rates of disorder in trauma-focused psychiatric epidemiology after major emergencies. International Journal of Epidemiology 38, 1045-1048.

Shonkoff JP, Garner AS (2012). The lifelong effects of early childhood adversity and toxic stress. Pediatrics 129, e232-246.

Silove D, Bateman CR, Brooks RT, Fonseca CA, Steel Z, Rodger J, Soosay I, Fox G, Patel V, Bauman A (2008). Estimating clinically relevant mental disorders in a rural and an urban setting in postconflict Timor Leste. Archives of General Psychiatry 65, 1205-1212.

Silove D, Brooks R, Bateman Steel CR, Steel Z, Hewage K, Rodger J, Soosay I (2009). Explosive anger as a response to human rights violations in post-conflict Timor-Leste. Social Science and Medicine 69, 670-676.

Silove D, Rees S, Tam N, Liddell B, Zwi A (2011). Staff management and capacity building under conditions of insecurity: lessons from developing mental health service and research programs in post-conflict Timor-Leste. Australasian Psychiatry 19, Suppl 1, S90-S94.

Soosay I, Silove D, Bateman-Steel C, Steel Z, Bebbington P, Jones PB, Chey T, Ivancic L, Marnane C (2012). Trauma exposure, PTSD and psychotic-like symptoms in post-conflict Timor Leste: an epidemiological survey. BMC Psychiatry 12, 229.

Steel Z, Chey T, Silove D, Marnane C, Bryant RA, van Ommeren M (2009). Association of torture and other potentially traumatic events with mental health outcomes among populations exposed to mass conflict and displacement. Journal of the American Medical Association 302, 537-549.

Themner L, Wallensteen P (2012). Armed conflicts, 19462011. Journal of Peace Research 49, 565-575.

Tol WA, Komproe IH, Thapa SB, Jordans MJ, Sharma B, De Jong JT (2007). Disability associated with psychiatric symptoms among torture survivors in rural Nepal. Journal of Nervous and Mental Disease 195, 463-469.

Tol WA, Kohrt BA, Jordans MJ, Thapa SB, Pettigrew J, Upadhaya N, De Jong JT (2010a). Political violence and mental health: a multi-disciplinary review of the literature on Nepal. Social Science and Medicine 70, 35-44.

Tol WA, Reis R, Susanty D, De Jong JT (2010b). Communal violence and child psychosocial well-being: qualitative findings from Poso, Indonesia. Transcultural Psychiatry 47, 112-135.

Tol WA, Barbui C, Galappatti A, Silove D, Betancourt TS, Souza R, Golaz A, van Ommeren M (2011a). Mental health and psychosocial support in humanitarian settings: linking practice and research. Lancet 378, 1581-1591.

Tol WA, Komproe IH, Jordans MJ, Susanty D, De Jong JT (2011b). Developing a function impairment measure for children affected by political violence: a mixed methods approach in Indonesia. International Journal for Quality in Health Care 23, 375-383. 
Tol WA, Patel V, Tomlinson M, Baingana F, Galappatti A, Panter-Brick C, Silove D, Sondorp E, Wessells M, van Ommeren M (2011c). Research priorities for mental health and psychosocial support in humanitarian settings. PLoS Medicine 8, e1001096.

Tol WA, Patel V, Tomlinson M, Baingana F, Galappatti A, Silove D, Sondorp E, van Ommeren M, Wessells MG, Panter-Brick C (2012). Relevance or excellence? Setting research priorities for mental health and psychosocial support in humanitarian settings. Harvard Review of Psychiatry 20, 25-36.

Tol WA, Song S, Jordans MJD (2013). Annual research review: resilience in children and adolescents living in areas of armed conflict: a systematic review of findings in low and middle-income countries. Journal of Child Psychology and Psychiatry 54, 445-460.

Van Duijl M, Nijenhuis E, Komproe IH, Gernaat HB, De Jong JT (2010). Dissociative symptoms and reported trauma among patients with spirit possession and matched healthy controls in Uganda. Culture, Medicine and Psychiatry 34, 380-400.
Ventevogel P, De Vries G, Scholte WF, Shinwari NR, Faiz H, Nassery R, Van Den Brink W, Olff M (2007).

Properties of the Hopkins symptom checklist-25 (HSCL-25) and the self-reporting questionnaire (SRQ-20) as screening instruments used in primary care in Afghanistan. Social Psychiatry and Psychiatric Epidemiology 42, 328-335.

Weiss MG, Saraceno B, Saxena S, van Ommeren M (2003). Mental health in the aftermath of disasters: consensus and controversy. Journal of Nervous and Mental Disease 191, 611-615.

WHO, UNHCR (2012). Assessing Mental Health and Psychosocial Needs and Resources: Toolkit for Humanitarian Settings. WHO: Geneva.

World Health Assembly (2006). Constitution of the World Health Organization (Basic Documents 45th edn). WHO: Geneva.

World Health Organization (2010). MhGAP Intervention Guide for Mental, Neurological and Substance Use Disorders in Non-Specialized Health Settings: Mental Health Gap Action Programme (mhGAP). WHO: Geneva. 